\title{
Comparison of various methods of ischaemic cardioprotection on vitality of rat heart grafts
}

\author{
Jana Hložková',2, Peter Scheer ${ }^{1,2}$, Ivana Uhríková ${ }^{3}$, Pavel Suchý Jr. ${ }^{2}$, Tomáš Parák², \\ Ota Hlinomaz ${ }^{1}$
}

\author{
${ }^{1}$ St. Anne’s University Hospital, International Clinical Research Center,
} Brno, Czech Republic

${ }^{2}$ University of Veterinary and Pharmaceutical Sciences Brno, Faculty of Pharmacy, Brno, Czech Republic ${ }^{3}$ University of Veterinary and Pharmaceutical Sciences Brno, Faculty of Veterinary Medicine, Brno, Czech Republic

Received September 9, 2016

Accepted May 31, 2017

\begin{abstract}
The aim of the study was to compare 4 modes of ischaemic cardioprotection using continuous prograde autologous blood perfusion of the coronary artery in two hypothermic modes (group A, B) or conventional protection by cooled Hartmann solution (group C) or cooled saline (group D) without perfusion of the graft. Male Wistar rats $(n=24)$ were divided into four groups $(A-D)$. In groups $\mathrm{A}\left(22-25^{\circ} \mathrm{C}\right)$ and $\mathrm{B}\left(4-8^{\circ} \mathrm{C}\right)$, blood perfusion rate was $10 \mathrm{ml} / \mathrm{h}$ and the graft was placed in a water bath. Groups C, D were initially rinsed with cold $\left(4-8^{\circ} \mathrm{C}\right)$ Hartmann solution $(\mathrm{C})$ and cold saline solution (D), next the graft was placed in a water bath of cold $\left(4-8^{\circ} \mathrm{C}\right)$ Hartmann solution (C) or saline solution (D). The observed time was $30 \mathrm{~min}$ after the implemented perfusion (A, B) or initial rinsing (C, D). At $30 \mathrm{~min}$, hearts of all the groups were perfused for $10 \mathrm{~min}$ with prograde-autologous arterialized blood at room temperature. At perfusion minute 10 , blood was collected for biochemical analysis (sample 1). Sample 2 involved blood from a portable syringe infusion pumps (in parallel with sample 1). Pairwise test differences between samples 1 and 2 were significant in all the groups as regards creatine kinase and lactate dehydrogenase values, sampling 1 values being always higher, while cardiac troponin I concentrations were nonsignificant in the same comparison. The heart rate during the final perfusion was identical in all the groups. Our study has demonstrated that all observed cardioprotection modes are useful for experimental heart grafting.
\end{abstract}

Blood hypothermic cardioprotection, crystaloid hypothermic cardioprotection

The model of heart heterotopic grafting/cardiac transplantation (HTx) allows the monitoring of extensive cases of myocardial damage without the risk of death of experimental animals and, as opposed to monitoring the same in in vitro models (isolated heart model), myocardial sanogenesis can be studied over rather long timelines. The need to solve the graft response to the host is the only major drawback.

The basis of success is good vitality of the graft, which applies not only to experiments. Unlike clinical practice in human medicine, where cardioplegia (a form of ischaemic myocardial protection) is constantly investigated as an inseparable part of cardiac and great vessel surgery, ischemic graft protection is not addressed as a separate issue in heart transplantation in experimental practice of small mammals and has not been comprehensively examined (Lee et al. 1970; Heron 1971; Olausson et al. 1984; Cramer et al. 1989; Lorat et al. 2011; Sá et al. 2012; Janssen et al. 2015; Mimic et al. 2016). Due to our modification of non-sutured heart transplantation, maintaining the right carotid artery for applying cells/substances directly into the graft, we were studying various easily accessible and common ways of ischaemic cardioprotection. The project aimed to verify the taking of a vital graft with ischaemic cardioprotection using continuous prograde

Address for correspondence:

MVDr. Jana Hložková, PhD

St. Anne's University Hospital Brno

International Clinical Research Center

Pekařská 53, 65691 Brno, Czech Republic
Tel: 731495768

E-mail: jana.hlozkova.ro@gmail.com

http://actavet.vfu.cz/ 
autologous blood perfusion of the coronary bed in two hypothermic modes $\left(22-25{ }^{\circ} \mathrm{C}\right.$; $4-8{ }^{\circ} \mathrm{C}$ ) in comparison with conventional protection by cold saline or Hartmann solution without perfusion of the graft.

\section{Materials and Methods}

The experiment included 24 male rats of the Wistar outbred strain, the weight ranging from $435 \mathrm{~g}$ to $590 \mathrm{~g}$. The rats were housed under conventional conditions and fed rat chow (MyPo, Biosta Blučina, Czech Republic), and tap water ad libitum. The animals were under general anaesthesia by ether induction followed by application of diazepam (2 mg/kg, Apaurin inj. $10 \mathrm{mg} / \mathrm{ml}$, Krka, Slovenia), ketamine $(35 \mathrm{mg} / \mathrm{kg}$, Narketan inj. $100 \mathrm{mg} /$ $\mathrm{ml}$, Vetoquinol, Czech Republic), and xylazine (5 mg/kg, Xylapan inj $20 \mathrm{mg} / \mathrm{ml}$, Vetoquinol, Czech Republic), all intramusculary. The right carotid artery was dissected and cannulated by blunt dissection. Heparin (Heparin Léčiva inj. sol. 5000 m.j./ml, Zentiva, Czech Republic), was injected intra-arterially (500 IU).

\section{Evaluation of ischaemic cardioprotection}

Rats were randomly divided equally into four groups (A to D) by drawing lots done by the lab assistant. Group A represented prograde perfusion of the coronary bed by autologous (arterial $=$ fully saturated blood) blood at room temperature $\left(22^{\circ} \mathrm{C}\right)$ at the rate of $10 \mathrm{ml} / \mathrm{h}$, with the graft placed in a water bath of saline at room temperature; group B was the same as group A, with only the water bath temperature being $4-8^{\circ} \mathrm{C}$. Group C represented an initial rinse with cold $\left(4-8^{\circ} \mathrm{C}\right)$ Hartmann solution, with the graft placed in a water bath of Hartmann solution at $4-8^{\circ} \mathrm{C}$. Group D represented an initial rinse with cold $\left(4-8^{\circ} \mathrm{C}\right)$ saline, with the graft placed in a water bath of saline at a temperature of $4-8{ }^{\circ} \mathrm{C}$. For groups A and B, grafts were connected to the transportable infusion syringe pump. For group C, the blood in the coronary vessels was initially flushed with $10 \mathrm{ml}$ of cooled $\left(4^{\circ} \mathrm{C}\right)$ Hartmann solution. Cooled saline $\left(4{ }^{\circ} \mathrm{C}\right)$ was used for group D, the procedure otherwise matching that for group C. Groups $\mathrm{C}$ and D were without perfusion for the subsequent $30 \mathrm{~min}$. Perfusion was preceded by neck vessel dissection, initial bleeding via the $22 \mathrm{G}$ cannula (NEO VENOPIC 1, Artsana I) in a. carotis into a heparinized syringe as far as apnoea. The next steps involved opening the chest, clamping the aorta, and ligating the branches of the ascending aorta (a. subclavia sin., a. carotis comm. sin.) and venous inputs of v. cava cran. sin., v. cava cran. dex., v. cava caudalis. In groups C and D, $10 \mathrm{ml}$ of cooled crystalloid solution (C Hartmann, D-saline) were applied into the heart via a. carotis communis dex, while a portable syringe infusion pumps was launched and continuous perfusion initiated in groups A and $\mathrm{B}$. The heart and the lungs were removed. The lung tissue, oesophagus, trachea, and mediastinum were dissected away from the heart in a water bath and vv. pulmonales were ligated. The water bath was saline at room temperature (group A); saline, cooler temperature (groups B and D); or retriggered Hartmann solution (group C). Truncus pulmonalis was cannulated for blood sampling. The observed time was $30 \mathrm{~min}$ after the implemented perfusion (A, B) or initial rinsing (C, D). At $30 \mathrm{~min}$, hearts of all the groups were perfused for $10 \mathrm{~min}$ with autologous arterialized blood at room temperature, sampled at the beginning of the experiment through a cannula in the right carotid artery. At $5 \mathrm{~min}$ of the rinsing process, all the blood from the right ventricle was sucked through the cannula placed in the pulmonary artery with subsequent sampling of all the newly flown blood for analysis (sample 1). The flow rate of the final rinsing was $20 \mathrm{ml} / \mathrm{h}$ with an initial bolus of $2 \mathrm{ml}$ of blood to remove the residual crystalloid solution.

During the experiment, blood was sampled as follows: sample 1 involved the blood of truncus pulmonalis after the introduction of final perfusion by autologous blood $(t=40 \mathrm{~min})$; sample 2 was the blood from the portable syringe infusion pumps (in parallel with sample 1).

For all samples, plasmatic activity of creatine kinase (CK) and lactate dehydrogenase (LDH) was determined (Cobas, Roche diagnostic D), in addition to the plasma level of cardiac troponin I (Rat Ultra Sensitive Cardiac Troponin-I, Life Diagnostics Ltd., U.K.). A "multiple" was computed of an increase in plasmatic activities/ concentrations between the blood entering the graft (sample 2) and that flowing out of the graft (sample 1) using the formula:

"Multiple" = sample 1 / sample 2 .

In addition, graft heart rate was measured at minutes 5 and 35 of the protocol.

\section{Statistical analysis}

Statistical evaluation was done using Statistica 6.0 (Statsoft Inc., Tulsa, U.S.A.). Normality was tested using Shapiro-Wilk test. For comparison among groups Kruskal-Wallis test was used and comparison among samplings was performed using Wilcoxon pair test for paired data set and Mann-Whitney test for non-paired data. The level of significance was set at $P<0.05$, if not specified otherwise.

\section{Results}

Graft ischaemic cardioprotection was assessed by changes in biochemical variables (creatine kinase $=\mathrm{CK}$, lactate dehydrogenase $=\mathrm{LDH}$, cardiac troponin $\mathrm{I}=\mathrm{cTnI}$ ), and their multiples, between blood entering and leaving the heart at $40 \mathrm{~min}$ from clamping the aorta (Tables 1-3). 
Table 1. Plasma activity values of creatine kinase ( $\mu \mathrm{kat} / \mathrm{l})$ and its multiple.

\begin{tabular}{lcrrrrr}
\hline \multicolumn{7}{c}{ CK } \\
\hline A1 & Median & Min & Max & Mean & SD & SEM \\
A2 & 19.90 & 15.23 & 57.60 & 25.82 & 16.07 & 6.56 \\
A multiple & 8.82 & 6.81 & 11.86 & 9.19 & 2.16 & 0.88 \\
B1 & 2.16 & 1.31 & 6.80 & 3.00 & 2.05 & 0.83 \\
B2 & 20.95 & 8.70 & 29.77 & 20.58 & 8.38 & 3.42 \\
B multiple & 6.40 & 3.02 & 11.52 & 6.33 & 3.14 & 1.28 \\
C1 & 2.82 & 1.89 & 9.85 & 3.92 & 2.96 & 1.20 \\
C2 & 10.81 & 7.22 & 13.67 & 10.49 & 2.42 & 0.99 \\
C multiple & 1.25 & 5.93 & 11.50 & 8.34 & 2.14 & 0.87 \\
D1 & 8.67 & 1.02 & 1.62 & 1.27 & 0.19 & 0.08 \\
D2 & 7.73 & 4.32 & 10.49 & 8.76 & 1.10 & 0.45 \\
D multiple & 1.17 & 1.01 & 1.93 & 6.87 & 1.59 & 0.65 \\
\hline
\end{tabular}

CK - creatine kinase, SD - standard deviation, SEM - standard error of the mean

Table 2. Plasma activity values of lactate dehydrogenase $(\mu \mathrm{kat} / \mathrm{l})$ and its multiple.

\begin{tabular}{lcccccc}
\hline \multicolumn{7}{c}{ LDH } \\
\hline Median & Min & Max & Mean & SD & SEM \\
\hline A2 & 7.96 & 6.17 & 19.13 & 9.47 & 4.86 & 2.00 \\
A multiple & 3.27 & 1.91 & 4.13 & 3.25 & 0.78 & 0.32 \\
B1 & 2.08 & 1.87 & 6.17 & 3.11 & 1.81 & 0.74 \\
B2 & 8.84 & 5.27 & 10.94 & 8.47 & 1.99 & 0.81 \\
B multiple & 2.37 & 1.23 & 3.66 & 2.54 & 0.91 & 0.37 \\
C1 & 3.67 & 1.50 & 8.90 & 4.01 & 2.57 & 1.05 \\
C2 & 3.83 & 2.46 & 5.65 & 3.97 & 1.18 & 0.48 \\
C multiple & 1.48 & 1.70 & 3.78 & 2.56 & 0.73 & 0.30 \\
D1 & 1.42 & 1.84 & 1.54 & 0.16 & 0.06 \\
D2 & 6.06 & 3.16 & 7.25 & 5.59 & 1.70 & 0.69 \\
D multiple & 1.99 & 2.11 & 4.20 & 2.70 & 0.76 & 0.31 \\
\hline
\end{tabular}

LDH - lactate dehydrogenase, STDEV- standard deviation, STERR - standard error of the mean

As shown by the results of Kruskal-Wallis test (Table 4), followed by Mann-White test (Table 5), there was no significant difference between the values of all groups as regards sampling 2, i.e. in the blood that was entering the graft, with regard to all biochemical variables (CK, LDH, cTnI).

\section{Creatine kinase}

The median of plasma activities of creatine kinase and its multiple after passing through the graft was the highest for group B and the lowest for group D (Table 1). Regarding sampling 1 , there was no significant difference between groups $A-B$ and C-D. In other combinations of groups (A-C, A-D, B-C, B-D), the difference was 
Table 3. Plasma concentration (pmol/l) of cardiac troponin I and its multiple - summary.

\begin{tabular}{lcccccc}
\hline \multicolumn{7}{c}{ Cardiac troponin I } \\
\hline A1 & Median & Min & Max & Mean & SD & SEM \\
A2 & 0.15 & 0.04 & 0.44 & 0.18 & 0.15 & 0.06 \\
A multiple & 0.04 & 0.04 & 0.04 & 0.04 & 0.00 & 0.00 \\
B1 & 3.70 & 0.82 & 11.15 & 4.60 & 4.01 & 1.63 \\
B2 & 0.29 & 0.04 & 0.94 & 0.34 & 0.33 & 0.14 \\
B multiple & 0.04 & 0.04 & 0.04 & 0.04 & 0.00 & 0.00 \\
C1 & 7.46 & 1.00 & 24.00 & 8.67 & 8.5 & 3.47 \\
C2 & 0.04 & 0.04 & 0.04 & 0.04 & 0.00 & 0.00 \\
C multiple & 0.04 & 0.04 & 0.04 & 0.04 & 0.00 & 0.00 \\
D1 & 1.00 & 1.00 & 1.00 & 1.00 & 0.00 & 0.00 \\
D2 & 0.04 & 0.04 & 0.04 & 0.04 & 0.00 & 0.00 \\
D multiple & 0.04 & 0.04 & 0.04 & 0.04 & 0.00 & 0.00 \\
\hline
\end{tabular}

SD - standard deviation, SEM - standard error of the mean

Table 4. $P$ values, Kruskal-Wallis test, after comparison of data files.

\begin{tabular}{lccc}
\hline Indicator & Sampling 1 & Sampling 2 & Multiple \\
\hline CK & 0.002 & ns & 0.002 \\
LDH & 0.003 & ns & 0.012 \\
cTNi & 0.002 & ns & 0.021 \\
\hline
\end{tabular}

CK - creatine kinase, cTnI - cardiac troponin I, LDH - lactate dehydrogenase, ns - non-significant difference

Table 5. $P$ values, Mann-Whitney test, after comparison of data files.

\begin{tabular}{|c|c|c|c|c|c|c|c|c|c|}
\hline \multirow{2}{*}{$P$} & \multicolumn{3}{|c|}{ Sampling 1} & \multicolumn{3}{|c|}{ Sampling 2} & \multicolumn{3}{|c|}{ Multiple } \\
\hline & CK & $\mathrm{LDH}$ & cTnI & CK & $\mathrm{LDH}$ & cTnI & CK & LDH & cTnI \\
\hline A vs B & ns & ns & ns & ns & ns & ns & ns & ns & ns \\
\hline A vs $C$ & 0.004 & 0.004 & 0.002 & ns & ns & ns & 0.006 & 0.004 & 0.040 \\
\hline A vs D & 0.004 & NS & 0.002 & ns & ns & ns & 0.025 & ns & 0.040 \\
\hline B vs $\mathrm{C}$ & 0.025 & 0.006 & 0.022 & ns & ns & ns & 0.004 & 0.01 & 0.020 \\
\hline B vs D & 0.016 & 0.037 & 0.022 & $\mathrm{~ns}$ & $\mathrm{~ns}$ & $\mathrm{~ns}$ & 0.006 & NS & 0.022 \\
\hline C vs D & ns & 0.090 & ns & ns & $\mathrm{ns}$ & ns & ns & ns & ns \\
\hline
\end{tabular}

CK - creatine kinase, cTnI - cardiac troponin I, LDH - lactate dehydrogenase, ns - non-significant difference

significant (Table 5). The results of pairwise tests between sampling 1 and 2 were significant in all the groups, sampling 1 values being always higher (Table 6).

\section{Lactate dehydrogenase}

The median of plasma activity of LDH and its multiple after passing through the graft was the highest for group $\mathrm{B}$ and the lowest for group $\mathrm{C}$ (Table 2). Regarding sampling 1, there was no significant difference between groups A-B, C-D, and A-D. In 
Table 6. $P$ values, Wilcox test, after comparison of data files.

\begin{tabular}{lcc}
\hline Pair & Groups & $P$ \\
\hline CK & A1 vs A2 & 0.028 \\
& B1 vs B2 & 0.028 \\
& C1 vs C2 & 0.028 \\
& D1 vs D2 & 0.028 \\
LDH & A1 vs A2 & 0.028 \\
& B1 vs B2 & 0.028 \\
& C1 vs C2 & 0.028 \\
& D1 vs D2 & 0.028 \\
cTnI & A1 vs A2 & ns \\
& B1 vs B2 & ns \\
& C1 vs C2 & ns \\
& D1 vs D2 & ns \\
\hline
\end{tabular}

CK - creatine kinase, cTnI - cardiac troponin I, LDH - lactate dehydrogenase, ns - nonsignificant difference maintained even for $60 \mathrm{~min}$ after suturing the skin. The heart rate diagram shows the differences between the groups (Fig. 1).

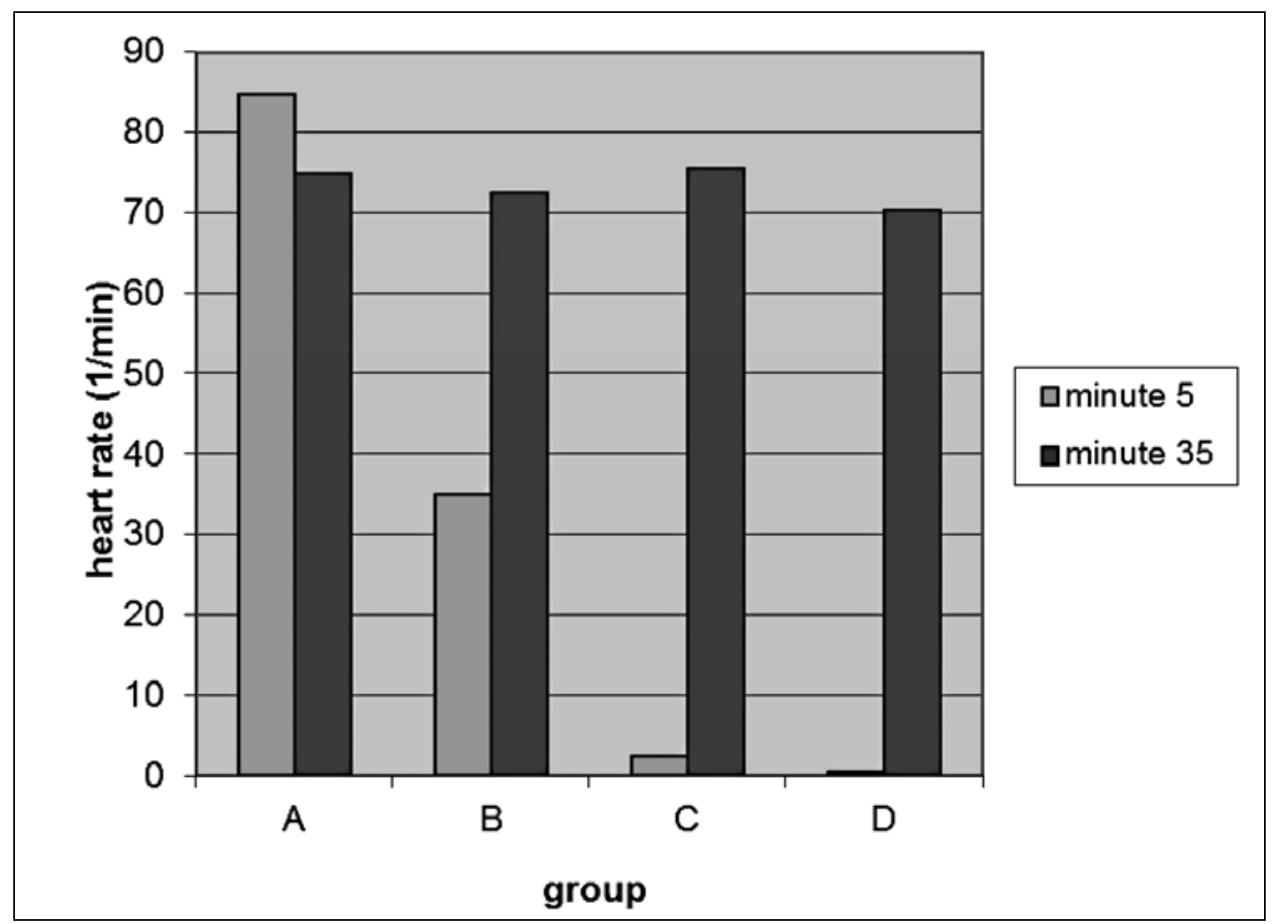

Fig. 1. Comparison of heart rates between all groups

other combinations of groups (A-C, B-C, B-D), the difference was significant (Table 5). The results of pairwise tests between sampling 1 and 2 were significant in all the groups, sampling 1 values being always higher (Table 6).

\section{Cardiac troponin I}

The median of plasma activities of cTnI and its multiple after passing through the graft was the highest for group B and the lowest for group $\mathrm{C}$ and D (Table 3). Regarding sampling 1, there was no significant difference between groups A-B and C-D. In other combinations of groups (A-C, B-C, B-D), the difference was significant (Table 5). In all groups, the results of pairwise tests between sampling 1 and sampling 2 were significant (Table 6).

After connection to the portable syringe infusion pumps with autologous blood, all grafts resumed activity spontaneously. They were attached to the acceptor, and their activity was 


\section{Discussion}

In experimental heart transplantation in small mammals, ischaemic myocardial protection has not been historically considered an issue, the probable cause being a really good graft vitality under a very simple cardioprotection method using cooled or deep-chilled saline $(0.9 \% \mathrm{NaCl})($ Lee et al. 1970; Heron 1971; Olausson et al. 1984; Lorat et al. 2011) or Ringer solution (Remie 2000). In principle, this practice is similar to sampling the heart for transplantation in humans. Heart sampling in humans takes place in most cases as part of the multiple-organ sampling after completing sterno-and laparotomy, when abdominal organs are taken first, followed by the heart (Pirk 2008). After heparinization, the heart is always initially perfused by the cardioplegic solution and stored on ice, which typically involves frozen saline (Pirk 2008). Crystalloid cardioplegic solution is preferred, e.g. St. Thomas no. 2, always under the hypothermal mode. The heart is placed in sac 1 along with St. Thomas solution. The second solution of "zero" ice contains saline, and sac 3 is left empty. In addition, some authors recommend blood cardioplegia during the transplantation process alone, due to the needed good quality of ischaemic protection of the graft (Černý et al. 2002). In addition to ischaemic myocardium protection, cardioplegia used in cardiac surgery enables relaxation and asystole of the myocardium. This effect is achieved by a high concentration of potassium and magnesium in the solution applied. In recent years, various modifications have been used in blood cardioplegia, which employs blood mixed with a crystalloid cardioplegic solution or a short-acting beta-blocker (esmolol) under a hypothermia mode or as "warm heart surgery". Cardioplegic solutions can be applied anterogradely through the coronary arteries, a procedure that we chose as well, or retrogradely through the coronary sinus (Dominik 1998).

A common goal in taking grafts in animal experiments as well as human transplantation is the ischaemic protection and preservation of myocardium vitality. Experimental results from research on cardioplegia suggest that classical cold crystalloid cardioplegia is not the best solution and does not provide 100\% protection (Reichard and Opie 1989; Soncul et al. 1992a; Soncul et al. 1992b; Kerendi et al. 2006; Hsieh et al. 2007; Choi et al. 2007; Sodha et al. 2008; Oka et al. 2008; Khabbaz et al. 2008).

When training for taking grafts for modified non-sutured heart transplantation, autologous blood rinsing was used for easier detection of incorrect ligation of large vessels and particularly the pulmonary veins, or the visualization of injuries, especially those of the atrium, during the process. Surprisingly, it was found that when these training taking actions were underway, the heart remained vital throughout the prograde perfusion $(60-90 \mathrm{~min})$ at a relatively low blood flow $(10 \mathrm{ml} / \mathrm{h})$ and the temperature mode of "light hypothermia", i.e. at room temperature $\left(20-25^{\circ} \mathrm{C}\right)$, with the heart beating most of the time in a sinus rhythm over the period, sometimes with an AV block II to III. This finding led us to the idea of verifying the effect of different ways of grafting ischaemic protection in experimental practice, which are easily accessible, inexpensive, and easy to implement.

Our findings confirm the well-known general rule that low temperatures are protective for the myocardium, providing a basic level of protection. With the room temperature $\left(20-25^{\circ} \mathrm{C}\right)$ already having hypothermic effects, the fact was adhered to throughout the groups. The monitored myocardial necrosis indicators, i.e. CK, LDH and cTnI, were selected with regard to the normal laboratory profile in patients with myocardial infarction. The short monitoring period $(30 \mathrm{~min}+10 \mathrm{~min})$ is the natural limit of our study but it actually reflects the reality of everyday experimental practice, when the graft is sewn within 30-40 min after taking. The advantage of our model is the fact that any increase in $\mathrm{CK}$ and cTnI between the blood flowing into and leaving the graft comes at the expense of the myocardium and is not distorted by other organs or tissues. For LDH, it is of course 
possible that it originates from the erythrocytes, this is a rather hypothetical option. Statistical comparison of the above-mentioned indicators of myocardial necrosis for blood entering the graft showed no differences between the groups. Pairwise comparison of samples per group substantiates the statement that cTnI levels between blood entering and exiting the graft did not differ significantly. On the other hand, LDH and CK levels significantly increased, with the lowest increase seen in crystalloid groups (C and D). cTnI is considered to be the most important and precise marker for myocardial necrosis (Hlinomaz 2003), with the methods monitored being equal in this regard although the values in "blood" groups (A and B) significantly differed from those in crystalloid groups $(\mathrm{C}, \mathrm{D})$, plus they were higher.

The refrigerated saline led, in almost each case, to asystole, whereas refrigerated Hartmann solution resulted in bradycardia not exceeding four beats per min. Blood perfusion at room temperature (blood A) was maintaining HR within the range of 80-90/ min. Blood perfusion using blood at room temperature and the heart in a bath at cooler temperature (group B) was associated with the rate of $35 / \mathrm{min}$. There was a unification of the heart rate at $70-75 / \mathrm{min}$ seen in all the groups after conducting final blood perfusion.

In conclusion, the graft vitality was satisfactory for all the observed modes of ischaemic protection. From the laboratory analysis aspect, crystalloid solutions under deep hypothermia in the time window of $30 \mathrm{~min}$ of cold ischaemia are better than autologous blood perfusion. Benefits of blood perfusion at room temperature include the method's simplicity, possibility of standardizing, and the ability to better monitor the quality of ligation and graft injury in taking, which is to be appreciated by beginners, in particular.

\section{Acknowledgements}

The study was supported by the Project no. LQ1605 from the National Program of Sustainability II (MEYS $\mathrm{CR})$ and by the project FNUSA-ICRC no. CZ.1.05/1.1.00/02.0123 (OP VaVpI).

\section{References}

Cerny S, Pavel P, Pirk J, Hola I, Brezina A, Sedlacek J, Straka F, Hegarova M, Malek I, Schubert T, Vetter H, Owen P 2002: Donor myocardial protection using secondary blood cardioplegia during heart transplantation: prospective randomized study in 100 patients. J Heart Lung Transpl 21: 61-62

Choi SU, Lee HW, Lim HJ, Yoon SM, Chang SH 2007: The effects of propofol on cardiac function after 4 hours of cold cardioplegia and reperfusion. J Cardiothorac Vasc Anesth 21: 678-682

Cramer DV, Qian S, Harnaha J, Chapman FA, Estes LW, Starzl TE, Makowka L 1989: Cardiac Transplantation in the Rat: I. The Effect of Histocompatibility Differences on Graft Arteriosclerosis. Transplantation 47: 414-419

Dominik J 1998: Antiischemic protection of myocardium in: Dominik J: Cardiosurgery. Grada Publ., Praha, pp 16-19

Heron I 1971: A technique for accessory cervical heart transplantation in rabbits and rats. Acta Pathol Microbiol Scand 79: $366-372$

Hlinomaz O 2003: Acute coronary syndromes in: Špinar J, Vítovec J et al.: Ischaemic heart disease. Grada Publ., Praha pp 160-200

Hsieh YJ, Wakiyama H, Levitsky S, McCully JD 2007: Cardioplegia and diazoxide modulate STAT3 activation and DNA binding. Ann Thorac Surg 84: 1272-1278

Janssen C, Kellermann S, Münch F, Purbojo A, Cesnjevar RA, Rüffer A 2015: Myocardial protection during aortic arch repair in a piglet model: Beating heart technique compared with crystalloid cardioplegia. Ann Thorac Surg 100: $1758-1766$

Kerendi F, Kirshbom PM, Halkos ME, Wang NP, Kin H, Jiang R, Zhao ZQ, Kanter KR, Guyton RA, VintenJohansen J 2006: Thoracic Surgery Directors Association Award. Cobalt chloride pretreatment attenuates myocardial apoptosis after hypothermic circulatory arrest. Ann Thorac Surg 81: 2055-2062

Khabbaz KR, Feng J, Boodhwani M, Clements RT, Bianchi C, Sellke FW 2008: Nonischemic myocardial acidosis adversely affects microvascular and myocardial function and triggers apoptosis during cardioplegia. $\mathrm{J}$ Thorac Cardiovasc Surg 135: 139-146

Lee S, Willoughby WF, Smallwood CJ, Dawson A, Orloff MJ 1970: Heterotopic heart and lung transplantation in the rat. Am J Pathol 59: 279-298

Lorant T, Emanuelsson C, Quach M, Tufveson G 2011: Graft morfology correlates with fibroblast activity in cardiac allograft rejection. APMIS 119: 588-596 
Mimic B, Ilic S, Vulicevic I, Milovanovic V, Tomic D, Mimic A et al. 2016: Comparison of high glucose concentration blood and crystalloid cardioplegia in paediatric cardiac surgery: a randomized clinical trial. Interact CardioVasc Thorac Surg 22: 553-560

Oka N, Wang L, Mi W, Zhu W, Honjo O, Caldarone CA 2008: Cyclosporine A prevents apoptosis-related mitochondrial dysfunction after neonatal cardioplegic arrest. J Thorac Cardiovasc Surg 135: 123-130

Olausson M, Mjörstendt L, Lindholm L, Brynger H 1984: Non-suture organ grafting to the neck vessels in rats. Acta Chir Scand 150: 463-467

Pirk J 2008: Surgical technique. In: Pirk J, Málek I et al.: Heart Transplantation. Karolinum, Praha, pp 92-96

Reichart B, Opie LH 1989: Adenosine cardioplegia. Adenosine versus potassium cardioplegia: effect on cardiac arrest and postischemic recovery in the isolated rat heart. J Thorac Cardiovasc Surg 98: 1057-1065

Remie R 2000: Experimental surgery In: Krinke GJ (ed): The Handbook of Experimental Animals - the Laboratory Rat. Academic Press, London, pp 523-560

Sá MP, Rueda FG, Ferraz PE, Chalegre ST, Vasconcelos FP, Lima RC 2012: Is there any difference between blood and crystalloid cardioplegia for myocardial protection during cardiac surgery? A meta-analysis of 5576 patients from 36 randomized trials. Perfusion 27: 535-546

Sodha NR, Clements RT, Bianchi C, Sellke FW 2008: Cardiopulmonary bypass with cardioplegic arrest activates protein kinase $C$ in the human myocardium. J Am Coll Surg 206: 33-41

Soncul H, Ersöz A, Gökgöz L, Karasu C, Ayrancioğlu K, Sinci V, Altan M 1992a: Cardioplegia with adenosine and adenosine triphosphate in isolated Guinea pig heart. Jpn Heart J 33: 843-850

Soncul H, Gökgöz L, Karasu C, Ayrancioğlu K, Ersöz A, Altan M, Yener A. 1992b: Comparison of potassium and adenosine cardioplegia with or without verapamil in the isolated guinea pig heart. Gen Pharmacol 23: 89-93 